\title{
The readiness of emergency and trauma care in low- and middle-income countries: a cross-sectional descriptive study of 42 public hospitals in Albania
}

Rifat Latifi ${ }^{1}{ }^{2 *}$, Jayleen K. L. Gunn ${ }^{2,3}$, John A. Stroster ${ }^{1}$, Edmond Zaimi ${ }^{4}$, Fatos Olldashi ${ }^{5}$, Agron Dogjani ${ }^{6}$, Mihal Kerci ${ }^{7}$, Xheladin Draçini ${ }^{8}$, Julian Kuçani ${ }^{2}$, Zhaneta Shatri ${ }^{9}$, Agim Kociraj ${ }^{9}$, Arian Boci ${ }^{2}$ and Ross I. Donaldson ${ }^{10}$

\begin{abstract}
Background: Traumatic injuries have become a substantial but neglected epidemic in low- and middle-income countries (LMICs), but emergency rooms (ERs) in these countries are often staffed with healthcare providers who have minimal emergency training and experience. The aim of this paper was to describe the specialized training, available interventions, and the patient management strategies in the ERs in Albanian public hospitals.
\end{abstract}

Methods: A cross-sectional descriptive study of 42 ERs in the Republic of Albania between September 5, 2014, and December 29, 2014 was performed. Assessment subcategories included the following: (1) specialized training and/ or certifications possessed by healthcare providers, (2) interventions performed in the ER, and (3) patient management strategies.

Results: Across the 42 ERs surveyed, less than half (37.1-42.5\%) of physicians and one third of nurses (7.1-26.0 \%) working in the ERs received specialized trauma training. About half (47.9-57.1 \%) of the ER physicians and one fifth of the nurses (18.3-22.9\%) possessed basic life support certification. This survey demonstrated some significant differences in the emergency medical care provided between primary, secondary, and tertiary hospitals across Albania (the significance level was set at 0.05). Specifically, these differences involved spinal immobilization $(p=0.01)$, FAST scan $(p=0.04)$, splinting $(p=0.01)$, closed reduction of displaced fractures $(p=0.02)$, and nurses performing cardiopulmonary resuscitation (CPR) $(p=0.01)$. Between 50.0 and $71.4 \%$ of the facilities cited a combined lack of training and supplies as the reason for not offering interventions such as rapid sequence induction, needle thoracotomy, chest tube insertion, and thrombolysis. Mass casualty triage was utilized among 39. $1 \%$ primary hospitals, $41.7 \%$ of secondary, and $28.6 \%$ of tertiary.

Conclusions: The emergency services in Albania are currently staffed with inadequately trained personnel, who lack the equipment and protocols to meet the needs of the population.

Keywords: World Health Organization, International Association for Trauma and Surgical Intensive Care, Guidelines for Essential Trauma Care, Low and middle-income countries (LMICS), Emergency medical care, Trauma care

\footnotetext{
* Correspondence: Latifi@surgery.arizona.edu; rifat.latifi@wmchealth.org

${ }^{1}$ Department of Surgery, Westchester Medical Center Health, 100 Woods Road, Valhalla, New York 10595, USA

${ }^{2}$ International Virtual e-Hospital (IVeH) Foundation, Hope, USA

Full list of author information is available at the end of the article
} 


\section{Background}

Progressive modernization and industrialization in lowand middle-income countries (LMICs) has led to a rapid increase in the use of motorized transport, frequently without associated safety policies and country infrastructure able to keep pace. Traumatic injuries have become a substantial but neglected epidemic in LMICs [1]. From 1990 to 2010, injuries represented $11.2 \%$ of disability-adjusted life years (DALYs), a widely accepted measurement of global disease burden [2].

Emergency medicine is a comparatively new specialty, particularly in LMICs, where there is a relative lack of medical staff specifically trained in emergency and trauma care. Often, there are few opportunities to receive such training in resource-limited settings, and those that do exist are usually cost-prohibitive. Human resource shortages also create a lack of local trainers for professional development courses aimed at the healthcare workforce in LMICs [3]. This results in emergency rooms staffed with rotating, off-service physicians or residents who often have minimal training and experience in emergency medicine [4]. A poor primary care system compounds this issue by increasing the acuity of patients presenting to the emergency room [5]. Thus, patients who need specialized emergent care may therefore experience delays in treatment or potentially inadequate care. A lack of structured emergency and trauma systems in LMICs, combined with an increased number of traumas, are major contributors to morbidity and mortality.

The Republic of Albania is an upper-middle-income country in southeastern Europe with three types of hospitals providing emergency services: primary, secondary, and tertiary [6]. Emergency rooms (ERs) associated with primary level hospitals offer access to few medical specialties, with limited laboratory and pathological services. ERs within secondary-level hospitals offer a wider range of specialties and subspecialties, affiliation with nursing schools, and provide teaching activities for allied health personnel. Tertiary hospitals possess ERs with highly specialized personnel affiliated with the medical school and represent the highest level of medical and surgical care in the country. At the tertiary level, the country has five hospitals, each with one or more of their own specialized ERs providing discipline-specific emergency services. The aim of this paper was to describe the specialized training, available interventions, and the patient management strategies in the ERs of Albanian public hospitals.

\section{Methods}

We conducted a cross-sectional study of hospitals in Albania, between September 5, 2014, and December 29, 2014, using a sample of 42 public hospital ERs and a questionnaire based on World Health Organization Guidelines for Essential Trauma Care (EsTC), modified and agreed upon by the Emergency and Trauma Care Physician Working Group of Albania. The University of Arizona's Intuitional Review Board (Protocol \#1509094379), the Ministry of Health in Albania, and the Chief of Staff or Hospital Director in each hospital approved the study.

\section{Survey measure}

EsTC guidelines encompass 260 items of human (staffing, training, skills) and physical (equipment, supplies) resources that are essential or desirable for trauma and emergency care, depending on the level of the facility [7]. We used selected elements from the EsTC guidelines as criteria for assessing emergency and trauma care within Albanian hospitals. Subcategories included the following: (1) specialized training and/or certifications possessed by healthcare providers, (2) interventions performed in the $\mathrm{ER}$, and (3) patient management strategies.

\section{Statistical analysis}

Using STATA version 14.0 (Stata Corporation, College Station, TX), a descriptive analysis was performed, with categorical variables presented as frequencies and percentages and continuous variables as means, standard deviations, and ranges. Fisher's exact tests for contingency tables were used to test for significance in proportions as the expected cell counts were less than five; the significance level was set at 0.05 .

\section{Results and discussion}

Table 1 shows the specialized training of medical personnel within the ERs of the 42 Albanian public hospitals surveyed. Roughly half of doctors in all settings

Table 1 Specialized training of Albanian medical professionals by emergency room type

\begin{tabular}{|c|c|c|c|c|c|c|}
\hline & \multicolumn{6}{|c|}{ Emergency room type } \\
\hline & \multicolumn{2}{|l|}{ Primary } & \multicolumn{2}{|c|}{ Secondary } & \multicolumn{2}{|l|}{ Tertiary } \\
\hline & \multicolumn{2}{|l|}{$(n=23)$} & \multicolumn{2}{|l|}{$(n=12)$} & \multicolumn{2}{|l|}{$\overline{(n=7)}$} \\
\hline & Yes (\%) & No $(\%)$ & Yes (\%) & No $(\%)$ & Yes (\%) & No $(\%)$ \\
\hline \multicolumn{7}{|c|}{ Basic Life Support (BLS) } \\
\hline Doctors & 56.7 & 43.3 & 47.9 & 52.1 & 57.1 & 42.9 \\
\hline Nurses & 18.3 & 81.7 & 22.9 & 77.1 & 21.4 & 78.6 \\
\hline \multicolumn{7}{|c|}{ Pediatric Advanced Life Support (PALS) } \\
\hline Doctors & 53.0 & 47.0 & 30.0 & 70.0 & 32.9 & 67.1 \\
\hline Nurses & 13.9 & 86.1 & 14.2 & 85.8 & 14.3 & 85.7 \\
\hline \multicolumn{7}{|c|}{ Advanced Cardiovascular Life Support (ACLS) } \\
\hline Doctors & 44.3 & 55.7 & 40.8 & 59.2 & 28.6 & 71.4 \\
\hline Nurses & 7.8 & 92.2 & 23.0 & 77.0 & 12.9 & 87.1 \\
\hline \multicolumn{7}{|c|}{ Trauma Training Course (BTLS/ATLS/PTLS/ITLS) } \\
\hline Doctors & 38.7 & 61.3 & 42.5 & 57.5 & 37.1 & 62.9 \\
\hline Nurses & 13.9 & 86.1 & 26.0 & 74.0 & 7.1 & 92.9 \\
\hline
\end{tabular}


had Basic Life Support (BLS) training, but only about one fifth of nurses. Approximately half of physicians working in the ERs had Pediatric Advanced Life Support (PALS) training at primary hospitals, yet less than one third were trained at secondary and tertiary facilities. Less than half of physicians working in the ERs had received specialized trauma or advanced cardiovascular life support training, while less than one third of nurses possessed equivalent training.

Table 2 presents the few interventions offered in the ERs that reached statistical significance, demonstrating a difference by facility type. Our survey additionally found that $69.6 \%$ of primary hospitals, $75.0 \%$ of secondary hospitals, and $57.1 \%$ of tertiary hospitals were able to provide basic airway management to their ER patients. Three tertiary hospitals, two secondary hospitals, and two primary hospitals described being able to perform endotracheal intubation in the ER on a regular basis. Rapid sequence induction was offered in only one $(4.4 \%)$ of the primary ERs and two secondary and tertiary facilities each. Chest tube insertion and needle thoracotomy were not offered due to a combined lack of training and supplies in $52.2 \%$ of primary, $50.0 \%$ of secondary, and $71.4 \%$ of tertiary ERs.
Intraosseous infusion was not offered in $60.9 \%$ of primary, $41.7 \%$ of secondary, and $14.3 \%$ of tertiary hospitals. Central venous access (CVA) within the ER was routinely performed in $57.1 \%$ of tertiary, $16.7 \%$ of secondary, and $17.4 \%$ of primary hospitals. Deep peritoneal lavage was offered in only one ER for each category of facility. Joint dislocation reduction was offered in less than half of the primary and secondary ERs ( 47.8 and $41.7 \%$, respectively), while no tertiary hospitals reported offering this intervention, mostly due to a lack of equipment and/or medications. The use of aspirin for suspected or confirmed myocardial infarction was not offered in more than half of the primary and secondary ERs (52.2 and $58.3 \%$, respectively), whereas only one tertiary facility did not offer this treatment to patients.

Table 3 outlines organizational patient management strategies by ER category. Over half of primary, two thirds of secondary, and all but one tertiary ER had standard triage techniques in place. Mass casualty triage was utilized in the ERs of $39.1 \%$ primary, $41.7 \%$ secondary, and $28.6 \%$ of tertiary facilities. Nurses routinely performed cardiopulmonary resuscitation (CPR) at least some of the time in all of the tertiary hospitals; this was

Table 2 Interventions offered by emergency room type

\begin{tabular}{|c|c|c|c|c|c|c|c|}
\hline & \multicolumn{7}{|c|}{ Emergency room type } \\
\hline & \multirow{2}{*}{\multicolumn{2}{|c|}{$\begin{array}{l}\text { Primary } \\
(n=23)\end{array}$}} & \multirow{2}{*}{\multicolumn{2}{|c|}{$\frac{\text { Regional }}{(n=12)}$}} & \multirow{2}{*}{\multicolumn{2}{|c|}{$\frac{\text { Tertiary }}{(n=7)}$}} & \multirow[b]{3}{*}{$p$ value } \\
\hline & & & & & & & \\
\hline & $n$ & $\%$ & $n$ & $\%$ & $n$ & $\%$ & \\
\hline Spinal immobilization (cervical collar) & & & & & & & $0.01^{*}$ \\
\hline Offered in ER & 8 & 34.8 & 7 & 58.3 & 0 & 0.0 & \\
\hline Not offered_combined lack of training and equipment/meds & 9 & 39.2 & 2 & 16.7 & 7 & 100.0 & \\
\hline Not offered-lack of training & 3 & 13.0 & 3 & 25.0 & 0 & 0.0 & \\
\hline Not offered-lack of equipment/medications & 3 & 13.0 & 0 & 0.0 & 0 & 0.0 & \\
\hline Focused assessment with sonography for trauma (FAST scan) & & & & & & & $0.04^{*}$ \\
\hline Offered in ER & 2 & 8.7 & 4 & 33.3 & 3 & 42.9 & \\
\hline Not offered_combined lack of training and equipment/meds & 14 & 60.9 & 5 & 41.7 & 3 & 42.9 & \\
\hline Not offered-lack of training & 0 & 0.0 & 0 & 0.0 & 0 & 0.0 & \\
\hline Not offered_lack of equipment/medications & 7 & 30.4 & 3 & 25.0 & 1 & 14.2 & \\
\hline Splinting performed & & & & & & & $0.01^{*}$ \\
\hline Offered in ER & 11 & 47.8 & 9 & 75.0 & 0 & 0.0 & \\
\hline Not offered—combined lack of training and equipment/meds & 6 & 26.1 & 1 & 8.4 & 6 & 85.7 & \\
\hline Not offered-lack of training & 1 & 4.4 & 1 & 8.3 & 0 & 0.0 & \\
\hline Not offered_lack of equipment/medications & 5 & 21.7 & 1 & 8.3 & 1 & 14.3 & \\
\hline Closed reduction of displaced fractures & & & & & & & $0.02^{*}$ \\
\hline Offered in ER & 9 & 39.1 & 8 & 66.7 & 0 & 0.0 & \\
\hline Not offered—combined lack of training and equipment/meds & 9 & 39.1 & 1 & 8.3 & 5 & 71.4 & \\
\hline Not offered—lack of training & 3 & 13.1 & 2 & 16.7 & 0 & 0.0 & \\
\hline Not offered-lack of equipment/medications & 2 & 8.7 & 1 & 8.3 & 2 & 28.6 & \\
\hline
\end{tabular}

${ }^{*} p$ value $<0.05$ denoted statistical significance

${ }^{\text {a }}$ Significance based on Fisher's exact test 
Table 3 Patient management by emergency room type

\begin{tabular}{|c|c|c|c|c|c|c|c|}
\hline & \multicolumn{7}{|c|}{ Emergency room type } \\
\hline & \multicolumn{2}{|c|}{ Primary } & \multicolumn{2}{|c|}{ Secondary } & \multicolumn{3}{|c|}{ Tertiary } \\
\hline & \multicolumn{2}{|c|}{$(n=23)$} & \multicolumn{2}{|c|}{$(n=12)$} & \multicolumn{3}{|c|}{$(n=7)$} \\
\hline & $\bar{n}$ & $\%$ & $n$ & $\%$ & $n$ & $\%$ & $p$ value $^{a}$ \\
\hline Critically ill patients resuscitated & & & & & & & 0.36 \\
\hline No & 4 & 17.4 & 2 & 16.7 & 3 & 42.9 & \\
\hline Yes & 19 & 82.6 & 10 & 83.3 & 4 & 57.1 & \\
\hline Standard hospital triage & & & & & & & 0.42 \\
\hline No & 10 & 43.5 & 4 & 33.3 & 1 & 14.3 & \\
\hline Yes & 13 & 56.5 & 8 & 66.7 & 6 & 85.7 & \\
\hline Mass casualty triage (START) & & & & & & & 0.68 \\
\hline No & 14 & 60.9 & 7 & 58.3 & 5 & 71.4 & \\
\hline Yes & 9 & 39.1 & 5 & 41.7 & 2 & 28.6 & \\
\hline Vital signs checked routinely & & & & & & & 0.08 \\
\hline No & 11 & 47.8 & 9 & 75.0 & 1 & 14.3 & \\
\hline Yes & 12 & 52.2 & 3 & 25.0 & 6 & 85.7 & \\
\hline Nurses routinely performed CPR & & & & & & & $0.01^{*}$ \\
\hline Never & 12 & 52.2 & 2 & 16.7 & 0 & 0.0 & \\
\hline Yes, sometimes & 7 & 30.4 & 8 & 66.7 & 2 & 28.6 & \\
\hline Yes, always & 4 & 17.4 & 2 & 16.7 & 5 & 71.4 & \\
\hline Nurses use bag valve masks & & & & & & & 0.11 \\
\hline Never & 7 & 30.4 & 3 & 25.0 & 4 & 57.1 & \\
\hline Yes, sometimes & 11 & 47.8 & 7 & 58.3 & 0 & 0.0 & \\
\hline Yes, always & 5 & 21.7 & 2 & 16.7 & 3 & 42.9 & \\
\hline
\end{tabular}

* $p$ value $<0.05$ denoted statistical significance

${ }^{\text {a }}$ Significance based on Fisher's exact test

significantly different compared to the situation in $83.4 \%$ of the secondary hospitals and less than half (47.8\%) of the primary hospitals.

This assessment described a lack of readily available equipment and supplies among Albanian ERs to provide necessary treatments, as well as a need for improvements in the Albanian emergency medicine (EM) training model. There are various designs for EM systems and their corresponding training models around the world, typically classified as either the Anglo-American or the Franco-German systems. The Anglo-American system features skilled physicians in emergency departments and a utilization of paramedics for prehospital emergency medical services. In contrast, the Franco-German system has a highly developed prehospital emergency physician services, but more divided organization at the hospital level. The Franco-German model tends to triage emergencies to different subspecialty areas, with physicians in the ERs possibly not requiring the same breadth of training as those in the Anglo-American system, as they are not exposed to the same variety of emergent cases. Given that these two systems differ substantially in their approach, it is an important consideration when designing improvements to an EM training model [5].
At first glance, the Albanian emergency medical system appears to be more similar to the Franco-German model, as there are no true paramedics and its five tertiary hospitals each have their own specialized ERs. In fact, the main facility, the Mother Teresa Hospital, has six separate ERs, each focusing on its own specialty: internal medicine, infectious diseases, otorhinolaryngology and maxillofacial, surgery, psychiatry, and pediatrics. However, unlike the typical Franco-German model, Albania does not have highly developed prehospital emergency services. Additionally, less than $10 \%$ of injured patients arrive at tertiary hospitals by ambulance, causing multiple problems with the triaging of patients [8]. The recent trend of offering specialized postgraduate emergency medicine training to physicians, as well as a residency program in emergency medicine in Albania, indicates a potential shift more towards the AngloAmerican system. It is therefore imperative that any EM training programs developed for Albania take into account the current and future needs of the nation.

Regardless of the model adopted for emergency medicine in Albania, our survey results reveal a lack of equipment, supplies, and/or training regarding several standard treatments and interventions. For example, 
only four hospitals out of the total 42 surveyed reported being able to perform a needle thoracotomy to treat pneumothorax, while six hospitals in total offered chest tube insertion in the ER. The ERs of one primary hospital and two secondary facilities, but no tertiary hospitals, offered thrombolysis or coronary angiography. Approximately $60 \%$ of physicians working in ERs lack formalized trauma training, while nearly half of the ER physicians in tertiary hospitals and more than three quarters of the nurses lacked BLS training. In order to ensure an adequate number of trained healthcare workers across the entire nation, strategies should include collaboration across different ministries in Albania, such as health, finance, and education [3].

The Distance CME program associated with the Integrated Telemedicine and e-Health Program in Albania (ITeHP-AL) already offers a wide variety of lectures and training opportunities for healthcare workers across the country [9]. We recommend expansion of this established program to include certification courses in basic, advanced, and pediatric life support, as has previously been performed elsewhere [10]. Additionally, given the widespread lack of trauma training and related organizational management structures, such as mass casualty triage, courses in trauma and eventually emergency preparedness and disaster relief would also be most beneficial.

Less than $10 \%$ of the seriously injured are transported to a hospital via ambulance, likely indicating a gap in prehospital emergency care [8]. While the emergency and trauma systems are being improved in Albania, one step that can be taken is to educate laypersons as first responders, which the World Health Organization has recommended as a critical step in establishing effective emergency medical services in LMICs [11]. Not only could the telemedicine infrastructure deliver medical training to healthcare workers but it could also be a low-cost venue to educate and train the citizens of Albania as well.

There continues to be a great divide in LMICs between clinical research findings and their application in everyday clinical practice, an issue that is most crucial for highly effective interventions that are largely ignored. A survey across ten LMICs found that healthcare practitioners are more likely to change their clinical practice if research has been performed and/or published in their own country, compared to outside the country [12]. It is therefore important that LMICs continue to perform high-quality research, rather than merely trying to adopt established standards from abroad. For example, there is a need for studies in LMICs that compare the trauma treatment within hospitals staffed with Advanced Trauma Life Support (ATLS) training to those without ATLS-trained staff in hospitals [13].

Although we surveyed 42 public hospital ERs in Albania, due to a lack of true randomization, our ability to generalize our results across the entire country remains unclear. Our data are also limited by the fact that survey responses were provided by hospital directors and leadership, which constitutes a biased source of reporting, although surveyors attempted to verify responses with tours of each ER. Finally, we did not obtain a list of qualifications and previous training from the Ministry of Health for each physician currently working in an ER, which would have provided a more complete impression of the readiness of these healthcare professionals.

\section{Conclusions}

This study was the first assessment of emergency and trauma service personnel in Albania using the EsTC guidelines. It provides an objective status of 42 different Albanian public hospital ERs across the country and can serve as a guide for focusing future development resources. The assessment has identified several areas for improvement that are essential to decreasing Albania's high rate of morbidity and mortality from injury and provided suggestions how these deficiencies could be corrected through the modification of existing services.

\section{Acknowledgements \\ The authors would like to thank the members of the Emergency and Trauma Care Physician Working Group of Albania: Dr. Xheladin Draçini, Deputy Dean of Faculty of Medicine and Professor of Surgery; Dr. Edmond Zaimi, Head of Emergency Medicine, Program Director of Emergency Medicine Department and Program Director of Emergency Medicine Residency, TUHC "Mother Teresa"; Fatos Olldashi, Chief of Department of Neurosurgery, University Hospital of Trauma; Mihal Kerci, Professor of Anesthesiology and Intensive Care, University Hospital of Trauma; Dr. Agrom Dogjani; Dr. Eritian Tashi; Dr. Dritan Pasku; Mr. Evis Bakiu; Mr. Julian Kucani; and Ms. Anduena Ylli. This is an original work and has not been previously submitted for publication.}

\section{Funding}

The study received funding from the US Agency for International Development (USAID) in Albania, Integrated Telemedicine and e-Health Project (contract no. 182-A-00-09-00101-00).

\section{Authors' contributions}

This manuscript has been read and approved by all the authors, and the requirements for authorship have been met, and that each author believes that the manuscript represents honest work.

\section{Competing interests}

The authors declare that they have no competing interests.

\section{Author details}

${ }^{1}$ Department of Surgery, Westchester Medical Center Health, 100 Woods Road, Valhalla, New York 10595, USA. ${ }^{2}$ International Virtual e-Hospital (IVeH) Foundation, Hope, USA. ${ }^{3}$ Department of Epidemiology and Biostatistics, University of Arizona, Tucson, AZ 85721, USA. "TUHC "Mother Teresa" Hospital, Tirana, Albania. ${ }^{5}$ Department of Neurosurgery, University Hospital of Trauma, Tirana, Albania. ${ }^{6}$ University Trauma Hospital, Tirana, Albania.

${ }^{7}$ Anesthesiology and Intensive Care, University Hospital of Trauma, Tirana, Albania. ${ }^{8}$ Faculty of Medicine \& Surgery, University of Tirana, Tirana, Albania. ${ }^{T}$ The United States Agency for International Development (USAID)/Albania, Tirana, Albania. ${ }^{10}$ Department of Emergency Medicine, Harbor-UCLA Medical Center, David Geffen School of Medicine at UCLA, Los Angeles, CA 90095 , USA. 
Received: 7 December 2015 Accepted: 2 September 2016

Published online: 07 October 2016

References

1. Dewberry L, McCullough C, Goss J, Hugar LA, Dente CJ, Sharma J. Trauma capacity in the central plateau department of Haiti. J Surg Res. 2014;192(1):34-40.

2. Murray CJ, Vos T, Lozano R, Naghavi M, Flaxman AD, Michaud C, et al. Disability-adjusted life years (DALYS) for 291 diseases and injuries in 21 regions, 1990-2010: a systematic analysis for the Global Burden of Disease Study 2010. Lancet. 2013;380(9859):2197-223.

3. Gopinathan U, Lewin S, Glenton C. Implementing large-scale programmes to optimise the health workforce in low- and middle-income settings: a multicountry case study synthesis. Trop Med Int Health. 2014;19(12):1437-56.

4. Donaldson RI, Shanovich P, Shetty P, Clark E, Aziz S, Morton M, et al. A survey of national physicians working in an active conflict zone: the challenges of emergency medical care in Iraq. Prehosp Disaster Med. 2012:27(02):153-61.

5. Nowacki AK, Landes M, Azazh A, Puchalski Ritchie LM. A review of published literature on emergency medicine training programs in low- and middleincome countries. Int J Emerg Med. 2013;6(1):26.

6. Albanian Center for Official Publication. Fletorja Zyrtare e Republikës së Shqipërisë. 2013. http://www.qbz.gov.al/botime/fletore_zyrtare/2013/ PDF-2013/31-2013.pdf. Accessed 1 Oct 2016

7. Mock C, Lormand JD, Goosen J, Joshipura M, Peden M. Guidelines for essential trauma care. Geneva: World Health Organization; 2004.

8. World Health Organization. Violence and injury prevention country profiles 2013: Albania. 2013. http://www.who.int/violence_injury_prevention/road_ safety status/2013/country_profiles/albania.pdf?ua=1. Accessed 1 Oct 2016.

9. Kruk ME. Emergency preparedness and public health systems lessons for developing countries. Am J Prev Med. 2008;34(6):529-34.

10. Donaldson RI, Mulligan DA, Nugent K, Cabral M, Saleeby ER, Ansari W, et al. Using tele-education to train civilian physicians in an area of active conflict: certifying Iraqi physicians in pediatric advanced life support from the United States. J Pediatr. 2011;159(3):507-9. e1

11. Callese TE, Richards CT, Shaw P, Schuetz SJ, Issa N, Paladino L, et al. Layperson trauma training in low- and middle-income countries: a review. J Surg Res. 2014:190(1):104-10.

12. Guindon GE, Lavis JN, Becerra-Posada F, Malek-Afzali H, Shi G, Yesudian CA, et al. Bridging the gaps between research, policy and practice in low- and middle-income countries: a survey of health care providers. CMAJ. 2010;182(9):E362-72.

13. Jayaraman S, Sethi D, Chinnock P, Wong R. Advanced trauma life support training for hospital staff. Cochrane Database Syst Rev. 2014:8:CD004173.

\section{Submit your manuscript to a SpringerOpen ${ }^{\circ}$ journal and benefit from:}

- Convenient online submission

- Rigorous peer review

- Immediate publication on acceptance

- Open access: articles freely available online

- High visibility within the field

- Retaining the copyright to your article 